\title{
Lahouari Addi,Lionel Obadia (éd.), Clifford Geertz. Interprétation et culture
}

Paris, Éditions des archives contemporaines, 2010, 191 p.

\section{Chantal Saint-Blancat}

\section{(2) OpenEdition}

\section{Journals}

Édition électronique

URL : http://journals.openedition.org/assr/23408

DOI : $10.4000 /$ assr.23408

ISSN : $1777-5825$

Éditeur

Éditions de l'EHESS

Édition imprimée

Date de publication : 31 décembre 2011

Pagination : 86

ISBN : 9782713223273

ISSN : 0335-5985

Référence électronique

Chantal Saint-Blancat, «Lahouari Addi,Lionel Obadia (éd.), Clifford Geertz. Interprétation et culture », Archives de sciences sociales des religions [En ligne], 156 | octobre-décembre 2011, document 156-2, mis en ligne le 14 février 2012, consulté le 21 septembre 2020. URL : http://journals.openedition.org/ assr/23408; DOI : https://doi.org/10.4000/assr.23408

Ce document a été généré automatiquement le 21 septembre 2020.

(c) Archives de sciences sociales des religions 


\title{
Lahouari Addi,Lionel Obadia (éd.), Clifford Geertz. Interprétation et culture
}

Paris, Éditions des archives contemporaines, 2010,191 p.

\author{
Chantal Saint-Blancat
}

\section{RÉFÉRENCE}

Lahouari ADDI,Lionel OBADIA (éd.), Clifford Geertz. Interprétation et culture, Paris, Éditions des archives contemporaines, 2010, 191 p.

1 Cet ouvrage collectif rassemble une partie des communications faites au colloque «Autour de Geertz» organisé à l'Université de Lyon en janvier 2008. Il réunit des contributions d'anthropologues, de sociologues et d'historiens. Le mérite de l'ouvrage est d'avoir su conjuguer une présentation de l'œuvre de Geertz avec un regard critique sur cette dernière. Le volume est organisé en trois parties: la première, remarquable de clarté, introduit en trois chapitres la démarche de Geertz et la rupture qu'elle introduit par rapport aux perspectives fonctionnalistes et structuralistes, la seconde est dédiée aux contradictions et limites qui caractérisent les concepts et la méthodologie d'une œuvre foisonnante, tandis que la dernière consacrée à la religion et en particulier à l'islam dissèque l'une des pages les plus controversées de l'anthropologie interprétative.

2 Les contributions de Addi, Laplantine et Assayag tracent un chemin critique dans la complexité de l'œuvre de Geertz, qui, malgré la richesse et la diversité de ses travaux, n'a jamais élaboré une théorie formalisée de l'action sociale mais inauguré une réflexion inédite sur la pratique anthropologique autour du concept de culture. Sa démarche est bien repositionnée par rapport à la tradition issue de Durkheim, ainsi que sa critique du positivisme et du structuralisme. Les trois auteurs s'attachent à montrer combien Geertz fut un précurseur et combien l'ethnographie, les gender et racial studies, 
les approches de terrain multidisciplinaires, le «tournant linguistique» et l'ensemble des sciences sociales de la deuxième moitié du $\mathrm{xx}^{\mathrm{e}}$ siècle doivent à sa réflexion.

3 Trois points demeurent au cœur de l'analyse: l'anthropologie interprétative, la transformation du concept de culture et la méthode de la «description dense». Contestant l'ethno-centrisme occidental de l'anthropologie, c'est à une anthropologie réflexive au sens wébérien du terme que Geertz nous convie, le sens que les acteurs eux-mêmes attribuent à leur vie quotidienne. Pour ce faire, il lui faut élaborer une nouvelle conception de la culture qu'il considère comme un ensemble de flux de symboles, de signes, de rites et d'institutions qu'il faut déchiffrer à partir du sens que leur confèrent les membres d'un groupe donné. C'est dans cette perspective herméneutique et phénoménologique qu'il inscrit la culture en proposant trois analogies: la culture comme jeu, comme scène dramatique et enfin comme texte, métaphore qu'il privilégie (Laplantine p.37). En voulant redonner sa place «au point de vue de l'indigène» l'interprétation est partie intégrante de la description. Cette «description dense», dont le souk de Sefrou (p.26 à 29) ou le combat de coqs à Bali sont des exemples paradigmatiques, permet de redonner sens aux actes sociaux en les resituant dans leur contexte historique et social. Le travail de Geertz dans son souci d'imprimer un aller-retour dialectique entre le local et le global nous présente le social comme un texte et chaque culture comme une singularité que l'on ne saurait inscrire dans une hiérarchie. Son œil attentif aux moindres détails significatifs, la rigueur de ses travaux ethnographiques ont contribué à imposer la culture comme système symbolique de communication susceptible de changements et de ruptures. Assayag a raison de souligner (p.44) qu'après Geertz «on n'observera plus jamais un combat de coqs comme avant».

4 Les textes de la deuxième partie proposent une réflexion critique de l'anthropologie symbolique.

5 Francine Saillant, rappelant que «l'une des grandes retombées du travail de Geertz fut d'avoir contribué, dans ses principes épistémologiques tout au moins, à la reconnaissance de la 'culture de l'autre' en tant que savoir» (p.55), s'interroge sur sa réception en particulier à travers la contestation du courant postcolonial. Dans la lignée de Geertz, elle approfondit le propos et soulève le cas des cultures minoritaires au sein du savoir national: les Afro-Brésiliens au Brésil et les autochtones au Canada. Selon elle, l'anthropologie postmoderne n'a pas su intégrer les savoirs marginalisés et le sens commun du savoir local cher à Geertz. Elle propose en réponse le développement d'une anthropologie politique des savoirs qui favorise l'agency des groupes périphériques au-delà d'un apparent consensus culturel.

6 Dans une même logique Lionel Obadia revient sur le concept de la culture comme texte et sur sa plasticité. Il distingue les "grands textes» des traditions non écrites des indigènes en prenant l'exemple de l'univers bouddhiste tibétain. Or le texte comme objet ethnographique, dans ses aspects normatifs, d'expertise légitime et de pouvoir, tend à ignorer les appropriations et interprétations pratiques des fameux «indigènes» chers à Geertz: «selon quelle textualité puis-je les inscrire? et en sont-ils moins bouddhistes pour autant?» (p.81). Voilà une question qui prend tout son sens dans l'analyse ethnographique de toutes les religions.

7 Hassam Rachik ouvre une stimulante observation méthodologique sur la crédibilité et le rôle de l'informateur en anthropologie, à partir de la machine à écrire de Geertz, mais en partant de l'expérience sur le terrain d'un anthropologue travaillant chez lui. 
Rappelant les scrupules, selon lui exagérés, de l'anthropologue occidental qui, en rupture avec l'éthique des travaux dits coloniaux, craint d'être accusé du vol des voix des informateurs (avec Clifford on parle de texte négocié, participatif), Rachik s'interroge: doit-on faire de telles concessions à l'informateur? Soulignant que «l'asymétrie sociale (inévitable) n'implique pas l'asymétrie morale» (p.104), il propose d'établir une éthique de compromis qui peut varier en fonction des informateurs et du terrain.

8 C'est dans la troisième partie dédiée à la conception symbolique de la religion et aux travaux sur l'islam marocain et indonésien qu'émergent les limites de l'application sur le terrain de la perspective geertzienne.

9 Camille Tarot passe d'abord en revue la conception culturelle du religieux qui apparaît comme un sous-système de sens dans la culture. Il s'agit d'une approche sémantique et les symboles sont ici aussi nécessaires à la cognition qu'à l'action (p.114). Le rituel, «ce comportement consacré», ensemble unique de symboles, apparaît comme le lien entre le sens commun, la conception du monde et l'éthos. Dans la seconde partie du texte, Tarot s'interroge sur le caractère véritablement opératoire de cette définition culturelle du religieux sur le terrain, en particulier balinais, et propose une fine analyse comparative de la place du sacré chez Mauss, Geertz et Lévi-Strauss. Selon l'auteur, la dépendance de Geertz à l'égard de l'analyse culturelle l'empêcherait en fait de relier la religion aux hiérarchies sociales qu'il sait pourtant si bien faire affleurer dans la violence rituelle du combat des coqs.

10 Les trois derniers textes, consacrés à la comparaison de l'islam dans les contextes culturels asiatiques et maghrébins et au rapport du religieux et du politique à travers le maraboutisme marocain, s'attachent à reconnaître à Geertz la primeur d'avoir su établir une rupture qui reconnaisse le religieux comme un fait culturel, de l'avoir étudié tel qu'il est vécu de l'intérieur par les acteurs et enfin d'avoir évité la réification de l'islam, de ne plus le présenter comme une réalité monolithique détachée du temps, de l'espace et du contexte culturel. Sa perspective comparatiste permet ainsi de faire place nette d'un essentialisme commun à certains islamistes ou islamologues et d'introduire une vision dynamique des changements religieux.

11 La déception est à la mesure de l'attente soulevée par l'ambition de cette nouvelle démarche méthodologique. La critique commune à Ferjani, El Adnani et Ferrié est résumée par l'historien (p.164): «la généralisation et la globalisation de la culture étudiée dans un souci comparatiste (le Maroc et l'Indonésie) l'ont emporté sur l'approche monographique». Bref, le terrain semble être passé au second plan. Dans son passage du local au global, sans problématiser, Geertz n'a pas su éviter les pièges du déterminisme qu'il a souvent dénoncés. En ce qui concerne le phénomène du maraboutisme, Geertz, influencé par les travaux fondateurs de l'époque coloniale, procède selon un schéma préétabli, le choix du cas du sultan Mohammed $V$ et du saint symbolique Al-Youssi n'étant pas représentatif du rapport entre religieux et politique au sein de l'islam marocain. L'historien qu'est El Adnani, à travers une excellente reconstruction de l'évolution du maraboutisme, remet les pendules à l'heure démontrant combien la relation entre sainteté et autorité politique est complexe et fluctuante, un jeu d'équilibre constant, un espace de négociation subtil et maîtrisé.

12 L'ouvrage dans sa perspective critique réhabilite également un vide dans la connaissance de l'anthropologie culturelle: l'œuvre de Geertz n'est pas totalement traduite en français et ne l'est aucunement en arabe. Les sciences sociales doivent 
beaucoup à Geertz, à son approche microscopique, textualiste, herméneutique, à son ambition de saisir le sens que donnent les populations étudiées aux symboles observables de leur vie quotidienne. Malgré les risques de généralisation encourus, ses travaux ethnographiques sont parmi les plus belles pages de l'anthropologie moderne. Les questions théoriques et méthodologiques qu'il souleva sont toujours au cœur des débats contemporains comme le démontre ce livre, en particulier l'ethnocentrisme des cultures. Pionnier de nombreux terrains, même ses erreurs servent encore aujourd'hui à la réflexivité nécessaire à tout chercheur soucieux de rigueur face à l'interprétation des faits sociaux observés. 